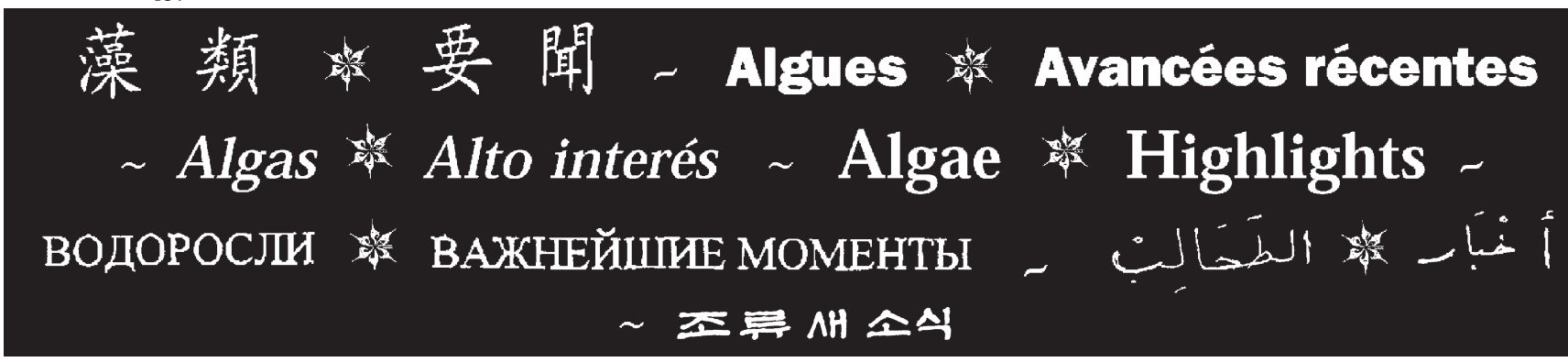

\title{
REFINING SPECIES BOUNDARIES IN ALGAE
}

For centuries, biologists have struggled with "the species problem"(i.e., the question of what comprises a species). Both the nature of species, and the criteria used to define them, have been intensely debated. The fundamental issue of whether species are real entities or the products of our propensity to classify biodiversity seems to have largely been settled in favor of the former view. Species are real, but perhaps not "real" in the sense that many would like. First, Darwin's evolutionary theory essentially killed the typological view of species and paved the way for a genealogical concept of species as groups of organisms linked by historical lines of descent. During the Modern Synthesis and under the influence of Dobzhansky (1935) and Mayr (1942), however, species became equivalent to groups of interbreeding organisms (the biological species concept). This view significantly promoted the idea of species as "fundamental units in biology," but differed significantly from Darwin's original view (Mallet 2010). A general lineage concept of species, which regards them as separately evolving metapopulation lineages in which mutation, selection, migration, and drift are acting independently (Wiley 1978), shifted the emphasis back to the genealogical nature of species. This resulted from making a clear and explicit distinction between the theoretical concept of species and the operational criteria that are used to diagnose taxa (De Queiroz 2007).

The concept that species are separately evolving metapopulation lineages, abetted by theoretical progress in phylogenetic and population genetic analyses, has led to the development of a wide array of methods aimed at identifying such lineages and hence delimiting species (Camargo and Sites 2013). Gene trees inferred from loci that bridge intraspecific and interspecific variation are vital to understanding the process of speciation and thus defining species boundaries. Whereas gene trees were in the past often used to delimit species on some kind of (often) subjective threshold (e.g., genetic distance), new model-based methods offer the promise to make species delimitation based on DNA sequence data more effective and objective. Several of these methods also provide statistical support regarding species boundaries, which is important in lineages that have recently diverged, or are in the process of speciation. In such recently diverging species complexes, species delimitation based on a single marker has progressively made way for methods incorporating multiple unlinked loci, which enable accounting for confounding processes like incomplete lineage sorting or hybridization (Dupuis et al. 2012).

Crucial in this paradigm shift regarding species delimitation, is that a general consensus is growing among systematic biologists that all other information that may aid as diagnostic characters for species is subordinate to DNA sequence data. In other words, species may or may not be morphologically or ecologically distinct or even reproductively isolated. Because species evolve separately, or because adaptation to specific niches drives their divergence, species are often phenotypically distinct, and in many cases these differences may thus serve as evidence relevant for species delimitation. However, morphological/ecological divergence and reproductive isolation is often lagging, making species delimitation using phenotypic data problematic in such cases. This is particularly true for recently diverged species, and in taxonomic groups that are morphologically simple, such as many algae (John and Maggs 1997, Leliaert et al. 2014).

The study by Montecinos et al. (2016), published in this issue, is an excellent example of how phycology has embraced this new trend in species delimitation. The paper focuses on the brown filamentous seaweed Ectocarpus, a genus with a notoriously difficult taxonomic history. Ectocarpus is widely distributed in intertidal pools and subtidal habitats of temperate regions in both hemispheres. Although one of the species, E. siliculosus, has become a genetic and genomic model organism for the brown algae (Cock et al. 2010), species diversity and the geographic distribution of this genus are not fully documented. The long and confounded taxonomic history of Ectocarpus has resulted in the description of nearly 500 species, subspecies, varieties and forms, many of which have later been synonymized or have an uncertain status. 
Within E. siliculosus, the taxon focused on by Montecinos et al. (2016), earlier breeding experiments performed by Dieter Müller showed the existence of pre- or post-zygotic reproductive barriers between isolates from different geographic areas (Müller 1976, 1988), suggesting a species complex. The presence of multiple cryptic species within what is now called the Ectocarpus subgroup siliculosi was later confirmed by DNA sequence data. StacheCrain et al. (1997), using nuclear and plastid markers, revealed several distinct clades from different geographic regions, corresponding generally with results from the cross-fertilization experiments. The number of clades increased with expanded taxon sampling (Peters et al. 2010a, b, 2015), but associating these clades with species boundaries remained tentative.

Montecinos et al. (2016) recognize 15 cryptic species within the Ectocarpus subgroup siliculosi (Fig. 1), and they base their conclusion on robust molecular data and statistical methods for DNA-based species delimitation. The analyses relied on 729 samples collected mainly along the European and Chilean coasts, and two unlinked loci: the mitochondrial cytochrome oxidase subunit $1 \quad(\operatorname{cox} 1)$ and the nuclear rDNA internal transcribed spacer 1 (ITS1). Two algorithmic species delimitation methods were employed. In a first method, a model that combines a coalescent model of intraspecific branching with a Yule model for interspecific branching (general mixed Yule-coalescent or GMYC model; Pons et al. 2006) was fitted to an ultrametric coxl tree, resulting in an estimation of 16 or 22 species, depending on a threshold parameter in the model. The GMYC method is based on expected differences between species-level evolutionary processes and populationlevel evolutionary processes, which are observable as a shift in branching rates in a gene tree, and can be statistically determined using a likelihood method. The second method used, "Automatic Barcode Gap Discovery" (Puillandre et al. 2012), relies exclusively on genetic distances between DNA sequences and aims at automatically detecting a discontinuity between inter- and intraspecific genetic distances, the so-called barcoding gap. Results of this analysis were slightly more conservative than the GMYC result. Finally, the topology of the coxl tree was compared with the ITS tree in a search for concordant terminal clades to serve as additional evidence for species boundaries. The rationale behind this approach is that within species, the mixing effects of recombination would result in different genealogies of unlinked loci, whereas between species, lineage sorting would lead to concordant genealogical histories. Hence, species can be identified if gene genealogies of multiple unlinked loci show congruent patterns of reciprocal monophyly (Avise and Ball 1990).

Because every species delimitation method has its weaknesses due to simplifying assumptions, and because different methods may yield different results, Carstens et al. (2013) recommended the use of a wide range of methods and, "place their trust in delimitations that are congruent across methods." This is also how Montecinos et al. (2016) proceeded: by taking a conservative combined approach, the authors settled on 15 species within the Ectocarpus subgroup siliculosi. The 15 species showed different patterns of geographic distribution, varying from rare species with narrow ranges to common cosmopolitan species (E. siliculosus and E. crouaniorum). Interestingly, one of the species with the smallest geographic range turned out to be the one with the sequenced genome (Cock et al. 2010), which is apparently restricted to the Peruvian Province and exhibits very low genetic diversity. As was suggested earlier, the genome-sequenced species is different from E. siliculosus, a globally distributed and genetically diverse species. Another interesting observation is that several of the different cryptic species have been observed to occupy different spatio-temporal ecological niches related to different tide levels and/or host specificity. For example, E. crouaniorum is consistently found higher on the shore than E. siliculosus in the North Atlantic. Finally, the nuclear and mitochondrial gene genealogies were found not to be completely concordant, which led the authors to conclude that some species still hybridize, or that incomplete lineage sorting occurred in these recently diverging lineages. These results support previous observations of incomplete reproductive barriers in culture and in the field (Müller and Kawai 1991, Peters et al. 2010a, b).

A nomenclatural question that emerges from the Montecinos et al. (2016) paper is whether all species should have a name, and by extension, if these names should be Latin binomials. Only two of the 15 delimited Ectocarpus species were named (E. siliculosus and E. crouaniorum), whereas the other species received numbers. More than 350 species names are available for Ectocarpus, and it is obvious that with the large number of synonyms, and the high level of observed cryptic diversity, the status of many of these names is uncertain. This uncertainty hampers the correct assignment of names to DNAdelimited species, as well as the description of new species based on DNA data. Ectocarpus is not an exception: an increasing number of algal studies fail to link DNA sequences to available taxon names (De Clerck et al. 2013). A commonly adopted solution is the use informal species identifiers (codes or numbers), but such a system may be untenable when such identifiers are not used consistently. An apparent solution for matching old names with DNA data is sequencing of type specimens. A number of studies have resolved taxonomic problems by integrating type material in molecular systematic studies (e.g., Hughey et al. 2001, Saunders and McDevit 2012a, Hind et al. 2014, Vieira et al. 2016). 


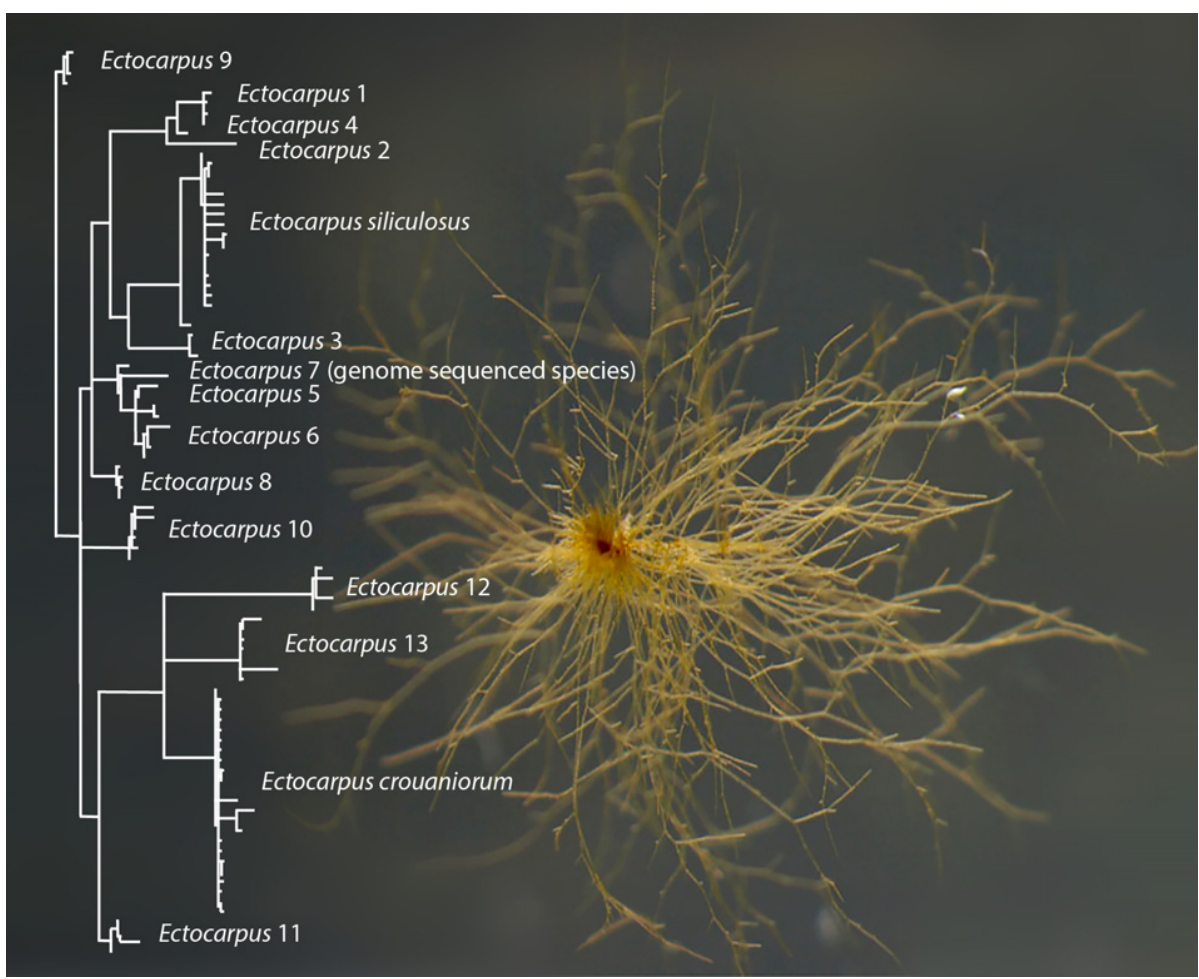

Fig. 1. Ectocarpus sp. strain NZKU 1-3 (CCAP 1310/56) in culture (photo by ODC), and cox1 phylogenetic tree of the Ectocarpus subgroup siliculosi showing the 15 DNA-delimited species by Montecinos et al. (2016). [Color figure can be viewed at wileyonlinelibrary.com].

However, sequencing type material is obviously not a general panacea because a large proportion of types are unavailable or cannot be sequenced due to technical limitations (Saunders and McDevit $2012 b)$. An alternative solution, which finds increasing acceptance in algal taxonomy is the selection and sequencing of epitypes (a specimen selected to serve as an interpretative type when the holotype or lectotype cannot be critically identified for purposes of the precise application of the name of a taxon; McNeill et al. 2012), but also this procedure is not entirely free of problems (Vieira et al. 2016). Most importantly, there is the need for a stable and functional system to communicate biological diversity. We leave open the question of whether this should be through formal Linnaean names or some other type of unique species identifiers.

The use of multi-locus data and model-based species delimitation methods is becoming increasingly common in algal studies, and is pointing phycologists toward more realistic species boundaries (Payo et al. 2013, Leliaert et al. 2014, Muangmai et al. 2014, Pardo et al. 2014, Sadowska-Deś et al. 2014, Vieira et al. 2014, Allewaert et al. 2015, Liu et al. 2015, Parkinson et al. 2015, Škaloud et al. 2015, Guillemin et al. 2016, Machín-Sánchez et al. 2016, Malavasi et al. 2016). Some of these studies also suggest that traditional or new species concepts in algae are often/still too broadly defined because of the imposition of strict thresholds for delimiting species, such as reciprocal monophyly and congruence of gene trees. Monophyly and genealogical concordance of unlinked loci is indeed expected among well-diverged species for the reasons described above. However, these criteria will probably fail to detect species boundaries between more recently diverged species where the lineage sorting is incomplete (Avise and Wollenberg 1997). Methods that extend coalescent models to the interspecific level aim at detecting signals of species divergence in gene trees without imposing a monophyletic threshold, and offer perspectives for testing species boundaries in young groups (Knowles and Carstens 2007). In the red alga Portieria, multispecies coalescence methods have been applied and resulted in the delimitation of multiple species with extremely narrow geographic ranges (Payo et al. 2013). Likewise in Fucus, one of the better studied algal groups, it has become clear that defining species boundaries can be confounded by shallow diversification and intricate evolutionary histories, including hybridization and introgression (Coyer et al. 2011, Zardi et al. 2011). Species delimitation in these species complexes will require additional data, sampled genome wide (e.g., microsatellites and single-nucleotide polymorphisms [SNPs]) to untangle confounding evolutionary events. Genomewide SNP data have proven indispensable to delimit species in recent radiations of animal and land plants, with hybridization occurring between species 
(Shaffer and Thomson 2007, Wagner et al. 2013, Pante et al. 2015, Boucher et al. 2016, Razkin et al. 2016). Algal species delimitation studies will undoubtedly follow, and will continue to advance our understanding of algal diversity.

FREDERIK LeLIAERT

Botanic Garden Meise, Nieuwelaan 38, 1860 Meise,
Belgium
Phycology Research Group, Biology Department,
Ghent University, 9000 Ghent, Belgium

and Olivier De Clerck Phycology Research Group, Biology Department,
Ghent University, 9000 Ghent, Belgium

Allewaert, C. C., Vanormelingen, P., Pröschold, T., Gómez, P. I., González, M. A., Bilcke, G., D'hondt, S. \& Vyverman, W. 2015. Species diversity in European Haematococcus pluvialis (Chlorophyceae, Volvocales). Phycologia 54:583-98.

Avise, J. C. \& Ball, R. M. 1990. Principles of genealogical concordance in species concepts and biological taxonomy. Oxf. Surv. Evol. Biol. 7:45-67.

Avise, J. C. \& Wollenberg, K. 1997. Phylogenetics and the origin of species. Proc. Natl. Acad. Sci. USA 94:7748-55.

Boucher, F., Casazza, G., Szövényi, P. \& Conti, E. 2016. Sequence capture using RAD probes clarifies phylogenetic relationships and species boundaries in Primula sect. Auricula. Mol. Phylogenet. Evol. 104:60-72.

Camargo, A. \& Sites, J. J. 2013. Species delimitation: a decade after the renaissance. In Pavlinov, I. [Ed.] The Species Problem - Ongoing Issues. InTech, New York, pp. 225-47.

Carstens, B. C., Pelletier, T. A., Reid, N. M. \& Satler, J. D. 2013. How to fail at species delimitation. Mol. Ecol. 22:4369-83.

Cock, J. M., Sterck, L., Rouzé, P., Scornet, D., Allen, A. E., Amoutzias, G., Anthouard, V., Artiguenave, F., Aury, J. M. \& Badger, J. H. 2010. The Ectocarpus genome and the independent evolution of multicellularity in brown algae. Nature 465:617-21.

Coyer, J., Hoarau, G., Costa, J., Hogerdijk, B., Serrão, E., Billard, E., Valero, M., Pearson, G. \& Olsen, J. 2011. Evolution and diversification within the intertidal brown macroalgae Fucus spiralis/F. vesiculosus species complex in the North Atlantic. Mol. Phylogenet. Evol. 58:283-96.

De Clerck, O., Guiry, M. D., Leliaert, F., Samyn, Y. \& Verbruggen, H. 2013. Algal taxonomy: a road to nowhere? J. Phycol. 49:215-25.

De Queiroz, K. 2007. Species concepts and species delimitation. Syst. Biol. 56:879-86.

Dobzhansky, T. 1935. A critique of the species concept in biology. Philos. Sci. 2:344-55.

Dupuis, J. R., Roe, A. D. \& Sperling, F. A. H. 2012. Multi-locus species delimitation in closely related animals and fungi: one marker is not enough. Mol. Ecol. 21:4422-36.

Guillemin, M. L., Contreras-Porcia, L., Ramírez, M. E., Macaya, E. C., Contador, C. B., Woods, H., Wyatt, C. \& Brodie, J. 2016. The bladed Bangiales (Rhodophyta) of the South Eastern Pacific: molecular species delimitation reveals extensive diversity. Mol. Phylogenet. Evol. 94:814-26.

Hind, K. R., Gabrielson, P. W., Lindstrom, S. C. \& Martone, P. T. 2014. Misleading morphologies and the importance of sequencing type specimens for resolving coralline taxonomy (Corallinales, Rhodophyta): Pachyarthron cretaceum is Corallina officinalis. J. Phycol. 50:760-4.

Hughey, J. R., Silva, P. C. \& Hommersand, M. H. 2001. Solving taxonomic and nomenclatural problems in Pacific
Gigartinaceae (Rhodophyta) using DNA from type material. J. Phycol. 37:1091-109.

John, D. M. \& Maggs, C. A. 1997. Species problems in eukaryotic algae: a modern perspective. In Claridge, M. F., Dawah, H. A. \& Wilson, M. R. [Eds.] Species: The Units of Biodiversity. Chapman \& Hall, London, pp. 83-107.

Knowles, L. L. \& Carstens, B. C. 2007. Delimiting species without monophyletic gene trees. Syst. Biol. 56:887-95.

Leliaert, F., Verbruggen, H., Vanormelingen, P., Steen, F., LópezBautista, J. M., Zuccarello, G. C. \& De Clerck, O. 2014. DNAbased species delimitation in algae. Eur. J. Phycol. 49:179-96.

Liu, S. L., Lin, S. M. \& Chen, P. C. 2015. Phylogeny, species diversity and biogeographic patterns of the genus Tricleocarpa (Galaxauraceae, Rhodophyta) from the Indo-Pacific region, including T. confertus sp. nov. from Taiwan. Eur. J. Phycol. 50:439-56.

Machín-Sánchez, M., Rousseau, F., Le Gall, L., Cassano, V., Neto, A. I., Sentíes, A., Fujii, M. T. \& María Candelaria, G. R. 2016. Species diversity of the genus Osmundea (Ceramiales, Rhodophyta) in the Macaronesian region. J. Phycol. 52:664-81.

Malavasi, V., Škaloud, P., Rindi, F., Tempesta, S., Paoletti, M. \& Pasqualetti, M. 2016. DNA-based taxonomy in ecologically versatile microalgae: a re-evaluation of the species concept within the coccoid green algal genus Coccomyxa (Trebouxiophyceae, Chlorophyta). PLoS ONE 11:e0151137.

Mallet, J. 2010. Group selection and the development of the biological species concept. Phil. Trans. R. Soc. B 365:1853-63.

Mayr, E. 1942. Systematics and the Origin of Species, from the Viewpoint of a Zoologist. Columbia University Press, New York, 334 pp.

McNeill, J., Barrie, F., Buck, W., Demoulin, V., Greuter, W., Hawksworth, D., Herendeen, P., Knapp, S., Marhold, K. \& Prado, J. 2012. International Code of Nomenclature for algae, fungi, and plants (Melbourne Code) Adopted by the Eighteenth International Botanical Congress Melbourne, Australia, July 2011. Koeltz, Koenigstein, Germany, 232 pp.

Montecinos, A. E., Couceiro, L., Peters, A. F., Desrut, A., Valero, M. \& Guillemin, M. L. 2016. Species delimitation and phylogeographic analyses in the Ectocarpus subgroup siliculosi (Ectocarpales, Phaeophyceae). J. Phycol. doi: 10.1111/jpy.12452.

Muangmai, N., West, J. A. \& Zuccarello, G. C. 2014. Evolution of four Southern Hemisphere Bostrychia (Rhodomelaceae, Rhodophyta) species: phylogeny, species delimitation and divergence times. Phycologia 53:593-601.

Müller, D. G. 1976. Sexual isolation between a european and an american population of Ectocarpus siliculosus (Phaeophyta). J. Phycol. 12:252-4.

Müller, D. G. 1988. Studies on sexual compatibility between Ectocarpus siliculosus (Phaeophyceae) from Chile and the Mediterranean Sea. Helgol. Meeresunters. 42:469-76.

Müller, D. \& Kawai, H. 1991. Sexual reproduction of Ectocarpus siliculosus (Ectocarpales, Phaeophyceae) in Japan. Jpn. J. Phycol. 39:151-5.

Pante, E., Abdelkrim, J., Viricel, A., Gey, D., France, S., Boisselier, M. C. \& Samadi, S. 2015. Use of RAD sequencing for delimiting species. Heredity 114:450-9.

Pardo, C., Lopez, L., Peña, V., Hernández-Kantún, J., Le Gall, L., Bárbara, I. \& Barreiro, R. 2014. A multilocus species delimitation reveals a striking number of species of coralline algae forming maerl in the OSPAR maritime area. PLOS ONE 9: e104073.

Parkinson, J. E., Coffroth, M. A. \& LaJeunesse, T. C. 2015. New species of Clade B Symbiodinium (Dinophyceae) from the greater Caribbean belong to different functional guilds: S. aenigmaticum sp. nov., S. antillogorgium sp. nov., S. endomadracis sp. nov., and S. pseudominutum sp. nov. J. Phycol. 51:850-8.

Payo, D. A., Leliaert, F., Verbruggen, H., D'hondt, S., Calumpong, H. P. \& De Clerck, O. 2013. Extensive cryptic species diversity and fine-scale endemism in the marine red alga Portieria in the Philippines. Proc. R. Soc. B 280:20122660.

Peters, A. F., Couceiro, L., Tsiamis, K., Küpper, F. C. \& Valero, M. 2015. Barcoding of cryptic stages of marine brown algae 
isolated from incubated substratum reveals high diversity in Acinetosporaceae (Ectocarpales, Phaeophyceae). Crypt. Algol. 36:3-29.

Peters, A. F., Mann, A. D., Cordova, C. A., Brodie, J., Correa, J. A., Schroeder, D. C. \& Cock, J. M. 2010a. Genetic diversity of Ectocarpus (Ectocarpales, Phaeophyceae) in Peru and northern Chile, the area of origin of the genome-sequenced strain. New Phytol. 188:30-41.

Peters, A. F., Van Wijk, S. J., Cho, G. Y., Scornet, D., Hanyuda, T., Kawai, H., Schroeder, D. C., Cock, J. M. \& Boo, S. M. 2010b. Reinstatement of Ectocarpus crouaniorum Thuret in Le Jolis as a third common species of Ectocarpus (Ectocarpales, Phaeophyceae) in Western Europe, and its phenology at Roscoff, Brittany. Phycol. Res. 58:157-70.

Pons, J., Barraclough, T. G., Gomez-Zurita, J., Cardoso, A., Duran, D. P., Hazell, S., Kamoun, S., Sumlin, W. D. \& Vogler, A. P. 2006. Sequence-based species delimitation for the DNA taxonomy of undescribed insects. Syst. Biol. 55:595-609.

Puillandre, N., Lambert, A., Brouillet, S. \& Achaz, G. 2012. ABGD, Automatic Barcode Gap Discovery for primary species delimitation. Mol. Ecol. 21:1864-77.

Razkin, O., Sonet, G., Breugelmans, K., Madeira, M. J., GómezMoliner, B. J. \& Backeljau, T. 2016. Species limits, interspecific hybridization and phylogeny in the cryptic land snail complex Pyramidula: the power of RADseq data. Mol. Phylogenet. Evol. 101:267-78.

Sadowska-Deś, A. D., Dal Grande, F., Lumbsch, H. T., Beck, A. Otte, J., Hur, J. S., Kim, J. A. \& Schmitt, I. 2014. Integrating coalescent and phylogenetic approaches to delimit species in the lichen photobiont Trebouxia. Mol. Phylogenet. Evol. 76:202-10.

Saunders, G. W. \& McDevit, D. C. 2012a. Acquiring DNA sequence data from dried archival red algae (Florideophyceae) for the purpose of applying available names to contemporary genetic species: a critical assessment. Botany 90:191-203.

Saunders, G. W. \& McDevit, D. C. 2012b. Methods for DNA barcoding photosynthetic protists emphasizing the macroalgae and diatoms. Methods Mol. Biol. 858:207-22.

Shaffer, H. B. \& Thomson, R. C. 2007. Delimiting species in recent radiations. Syst. Biol. 56:896-906.

Škaloud, P., Steinová, J., Řídká, T., Vančurová, L. \& Peksa, O. 2015. Assembling the challenging puzzle of algal biodiversity: species delimitation within the genus Asterochloris (Trebouxiophyceae, Chlorophyta). J. Phycol. 51:507-27.

Stache-Crain, B., Müller, D. G. \& Goff, L. J. 1997. Molecular systematics of Ectocarpus and Kuckuckia (Ectocarpales, Phaeophyceae) inferred from phylogenetic analysis of nuclear-and plastid-encoded DNA sequences. J. Phycol. 33:152-68.

Vieira, C., Camacho, O., Wynne, M. J., Mattio, L., Anderson, R. J., Bolton, J. J., Sansón, M. et al. 2016. Shedding new light on old algae: matching names and sequences in the brown algal genus Lobophora (Dictyotales, Phaeophyceae). Taxon 65:689-707.

Vieira, C., D'hondt, S., De Clerck, O. \& Payri, C. E. 2014. Toward an inordinate fondness for stars, beetles and Lobophora? Species diversity of the genus Lobophora (Dictyotales, Phaeophyceae) in New Caledonia. J. Phycol. 50:1101-19.

Wagner, C. E., Keller, I., Wittwer, S., Selz, O. M., Mwaiko, S., Greuter, L., Sivasundar, A. \& Seehausen, O. 2013. Genomewide RAD sequence data provide unprecedented resolution of species boundaries and relationships in the Lake Victoria cichlid adaptive radiation. Mol. Ecol. 22:787-98.

Wiley, E. O. 1978. The evolutionary species concept reconsidered. Syst. Zool. 21:17-26.

Zardi, G. I., Nicastro, K. R., Canovas, F., Ferreira Costa, J., Serrão, E. A. \& Pearson, G. A. 2011. Adaptive traits are maintained on steep selective gradients despite gene flow and hybridization in the intertidal zone. PLoS ONE 6:e19402. 